\title{
Olivier-Pierre Thébault, Rimbaud à la lumière du dyonisiaque nietzschéen
}

\section{Maria Emanuela Raffi}

\section{(2) OpenEdition}

1 Journals

\section{Edizione digitale}

URL: https://journals.openedition.org/studifrancesi/4763

DOI: $10.4000 /$ studifrancesi.4763

ISSN: 2421-5856

\section{Editore}

Rosenberg \& Sellier

\section{Edizione cartacea}

Data di pubblicazione: 1 avril 2012

Paginazione: 173

ISSN: 0039-2944

\section{Notizia bibliografica digitale}

Maria Emanuela Raffi, «Olivier-Pierre Thébault, Rimbaud à la lumière du dyonisiaque nietzschéen», Studi Francesi [Online], 166 (I | LVI) | 2012, online dal 30 novembre 2015, consultato il 19 novembre 2021. URL: http://journals.openedition.org/studifrancesi/4763 ; DOI: https://doi.org/10.4000/studifrancesi. 4763

Questo documento è stato generato automaticamente il 19 novembre 2021.

\section{(c) (1)}

Studi Francesi è distribuita con Licenza Creative Commons Attribuzione - Non commerciale - Non opere derivate 4.0 Internazionale. 


\title{
Olivier-Pierre Thébault, Rimbaud à la lumière du dyonisiaque nietzschéen
}

\author{
Maria Emanuela Raffi
}

\section{NOTIZIA}

OLIVIER-PIERRE THÉBAULT, Rimbaud à la lumière du dyonisiaque nietzschéen, «L'Infini», 115, 2011, pp. 78-91.

È nel comune denominatore della musica e del canto, o più precisamente, dell' «intrication de la poésie pensante et de la musique», che Thébaut associa in questo studio i nomi di Rimbaud e di Nietzsche. Riferendosi particolarmente alle Illuminations, l'A. raccoglie le occorrenze «dyonisiaques», particolarmente evidenti in quattro testi: «Barbare», «Matinée d'ivresse», «Angoisse» e «Antique», di cui propone un'analisi puntuale. L'elemento fondamentale di questa musica è riconosciuto nell'«accord dyonisiaque des contradictoires qui caractérise l'âme rimbaldienne», cui fa da corollario «le principe de renversement [...], la conversion de la douleur en jouissance» e dell'orrore in piacere. L'enumerazione e l'esplicitazione dei numerosi ossimori che caratterizzano i quattro testi considerati porta alla luce non solo il loro tessuto intensamente metaforico, ma, al di là di esso, «l'expérience d'une autre musique» che è l'esperienza «du langage lui-même, sans aucune dépendance envers la lettre». Anche la 'dissonanza' spesso esibita e rilevata nella musica rimbaudiana «consiste à déceler l'unité profonde du monde, portant la contradiction essentielle de celui-ci dans la musique» e risolvendola sempre nell'ambito musicale, poiché per Thébaut è al livello del suono (prima ancora che del senso) che si realizza la «conciliation sonore et émouvante» che costituisce «la signification générale» dei testi delle Illuminations. 